\title{
Formation of Poly-L-lysine Monolayers on Silica: Modeling and Experimental Studies
}

\author{
Dominik Kosior, Maria Morga,* Plinio Maroni, Michał Cieśla, and Zbigniew Adamczyk* \\ Cite This: J. Phys. Chem. C 2020, 124, 4571-4581 \\ Read Online
}

ABSTRACT: Modification of solid substrates by poly-L-lysine (PLL) layers has been widely employed in order to improve their biocompatibility, for promoting protein and cell immobilization for fabrication of biosensor arrays and antibacterial coatings. However, despite many studies conducted in the literature, there is a deficiency in a quantitative description of PLL adsorption processes. It is postulated that this becomes feasible by applying direct experimental techniques combined with thorough theoretical modeling. In this work, the kinetics of PLL adsorption on silica for various ionic strengths was determined in situ under controlled flow conditions using the optical reflectometry and the streaming potential methods. Both the initial adsorption rates and longer time kinetic runs were acquired and quantitatively interpreted in terms of the convective diffusion and the random sequential adsorption theoretical modeling based on the coarse-grained Monte Carlo approach. This unique combination of

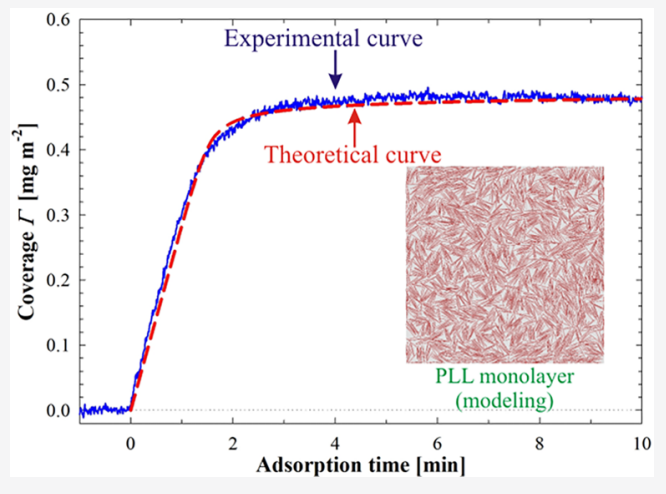
experimental and theoretical approaches enabled us to gain new insight into the mechanism of macroion adsorption controlled by the electrostatic interactions, which affect both the molecule conformations and the blocking effects. Besides significance for basic science, the results obtained in this work can be exploited for developing reliable procedures for preparing stable PLL monolayers of well-controlled coverage and electrokinetic properties.

\section{INTRODUCTION}

The ability of molecules to organize into various assemblies via molecular interactions at the solid/liquid interface has been widely employed in order to improve material properties. ${ }^{1-3}$ The typical example of macromolecules, successfully used for manufacturing functionalized solid substrates, is poly-L-lysine (PLL). PLL is a homopolymer of L-lysine (naturally occurring amino-acids), whose molecules are positively charged for a broad $\mathrm{pH}$ range, ${ }^{4}$ showing a strong tendency to adsorb on negatively charged surfaces in an aqueous environment. ${ }^{5,6}$

Modification of the solid surfaces by PLL has been widely employed in order to improve their biocompatibility, ${ }^{7,8}$ to prepare surfaces used for promoting protein and cell immobilization, ${ }^{9-12}$ for fabrication of biosensor arrays, ${ }^{13-15}$ and for antibacterial coatings. ${ }^{16-18}$ Moreover, PLL is of particular interest for medical applications, e.g., drug delivery $^{19-21}$ and disease diagnostics. ${ }^{22-24}$

Despite many studies conducted in order to investigate PLL conformation and structure, ${ }^{25-31}$ surface properties, ${ }^{32-34}$ and adsorption on various surfaces, ${ }^{35-41}$ the literature shows deficiency in a quantitative description of PLL deposition processes.

A comprehensive study of poly-L-lysine adsorption kinetics on silica was performed by Jiang et al. ${ }^{42}$ In the mentioned work, the optical reflectometry method and the impinging-jet cell were used for determining the maximum coverage of PLL, which monotonically increased with $\mathrm{pH}$ and ionic strength, attaining $0.8 \mathrm{mg} \mathrm{m}^{-2}$ at $\mathrm{pH} 10$ and ionic strength of $0.15 \mathrm{M}$ $(\mathrm{NaBr})$. This effect was qualitatively interpreted in terms of decreasing range of the lateral electrostatic interactions among adsorbed molecules and by the conformational changes of the molecule occurring at $\mathrm{pH}>9$. However, the lack of relevant physicochemical data such as the PLL molecule dimensions, shape, its surface area, and the effective charge caused these interesting results to not be quantitatively interpreted.

In this work, thorough experimental measurements of PLL adsorption on silica are performed by applying two complementary techniques: ${ }^{43,44}$ the optical reflectometry and the streaming potential. In the first method, following the change of the ratio of intensities of parallel and perpendicular polarized light reflected from a surface allows for online monitoring of the deposition process. ${ }^{45-48}$ The latter method monitors changes in the electrical properties of a modified solid surface ${ }^{49-51}$ due to the deposition of macromolecules and using electrokinetic models delivers quantitative information about the formed monolayer. ${ }^{52,53}$

Moreover, the experimental data are theoretically interpreted using the hybrid model where the bulk and surface mass

Received: November 20, 2019

Revised: January 14, 2020

Published: January 28, 2020 
transfer rate constants are calculated $a b$ initio using the diffusion coefficients of PLL molecules acquired from DLS measurements. On the other hand, the structure of the PLL layers controlling the blocking function is derived for various ionic strengths from the coarse-grained Monte Carlo modeling performed according to the random sequential adsorption (RSA) scheme. This unique combination of experimental and theoretical approaches enabled us to derive valid conclusions about the mechanism of PLL adsorption on silica. In particular, the electrostatic interaction driving force of this process and the prevailing side-on PLL molecule orientation are predicted.

\section{EXPERIMENTAL SECTION}

2.1. Materials. A pure crystalline poly-L-lysine hydrobromide, a cationic polyelectrolyte with molar mass of 75-189 $\mathrm{kg} \mathrm{mol}{ }^{-1}$ (manufacturer of the MALLS method), was purchased from Sigma-Aldrich, Merck KGaA, Darmstadt, Germany. The stock solution was prepared by dissolving a proper amount of PLL in $\mathrm{NaCl}$ solutions.

$\mathrm{NaCl}$ solutions of desired ionic strengths were prepared using deionized water obtained using the Milli-Q Elix \& Simplicity 185 purification system from Millipore SAS Molsheim, France, and analytical grade $\mathrm{NaCl}$ purchased from Sigma-Aldrich, Merck KGaA, Darmstadt, Germany.

Silicon wafers, p-type and boron doped, were purchased from Silchem, Freiberg, Germany. Studied solid surfaces were cleaned in a 1:1 mixture of $\mathrm{H}_{2} \mathrm{SO}_{4}$ and $\mathrm{H}_{2} \mathrm{O}_{2}$ for $30 \mathrm{~min}$ and then rinsed with Milli- $\mathrm{Q}$ water and afterward were immersed in $80{ }^{\circ} \mathrm{C}$ Milli-Q water for $30 \mathrm{~min}$. Finally, surfaces dried in a flow of nitrogen in the air plasma chamber for $30 \mathrm{~min}$. The precise thickness of the silica layer was determined in air by null ellipsometry (Multiskop, Optrel). ${ }^{54}$ The data were analyzed with a slab model whereby the refractive index at $633 \mathrm{~nm}$ of silicon and silica used was fixed at $3.85+0.02 i$ and 1.457, respectively. ${ }^{55,56}$ The thickness of the silica layer was equal to $3.2 \pm 0.4 \mathrm{~nm}$.

2.2. Methods. Optical Reflectometry. The adsorption of polyelectrolyte on a cleaned silica surface was monitored in situ using optical reflectometry in a stagnation point flow cell. A home-built fixed-angle reflectometer was equipped with a polarized green diode laser working with a wavelength of 532 nm (World Star Tech TECGL-532 Series), a cell consisting of a capped equilateral dispersing prism made out of quartz with a borehole of $r_{\mathrm{b}}=0.5 \mathrm{~mm}$ radius, a spacer ensuring a horizontal gap between the surface and the prism of $h=0.85 \mathrm{~mm}$, and a beam splitter and two diodes acquiring perpendicular $\left(R_{\mathrm{s}}\right)$ and parallel $\left(R_{\mathrm{p}}\right)$ components of the reflected beam. The solutions were pumped through the cell with flow rate $Q=1.02 \mathrm{~cm}^{3}$ $\min ^{-1}$

The reflectometry signal $R$ is related to the reflectances by

$$
R=C \frac{R_{\mathrm{p}}}{R_{\mathrm{s}}}
$$

where $C$ is an unknown instrumental constant that can be eliminated by normalizing the signal to its initial value, $R(0)$ :

$$
S(t)=\frac{R(t)-R(0)}{R(0)}
$$

The dry mass of the PLL film, $\Gamma(t)$, could then be calculated as

$$
\Gamma(t)=\frac{S(t)}{A}
$$

where $A$ is the sensitivity constant calculated from a homogeneous slab model, where the topmost layer corresponds to the adsorbed polyelectrolyte layer with refractive index calculated using the mixing law $47,48,57$

$$
n=n_{\mathrm{w}}+\frac{\Gamma}{H} \cdot \frac{d n}{d c}
$$

where $H$ is the thickness of the top layer; $n_{\mathrm{w}}=1.335$ is the refractive index of water; ${ }^{58}$ and $d n / d c=0.18 \mathrm{~cm}^{3} \mathrm{~g}^{-1}$ is the refractive index increment of a PLL solution. ${ }^{42,59}$ The refractive indices at $532 \mathrm{~nm}$ are $4.132+0.033 i$ and 1.461 for silicon and silica, respectively. ${ }^{55,56}$

A detailed description of the experimental setup has been given in previous papers. ${ }^{47,57}$

Streaming Potential Measurements. A homemade setup described in detail elsewhere ${ }^{52,60}$ was used to perform streaming potential measurements and to determine the zeta potential of PLL monolayers and their stability. In short, the main part of the cell is a parallel plate channel with the dimensions of $2 b_{c} \times 2 c_{c} \times L_{c}=0.027 \times 0.29 \times 6.2 \mathrm{~cm}$, formed by silica surfaces separated by a perfluoroethylene spacer. The streaming potential $E_{s}$ was measured using a pair of $\mathrm{Ag} / \mathrm{AgCl}$ electrodes as a function of the hydrostatic pressure difference $\Delta P$, causing the flow of an electrolyte through the channel. The overall cell electric conductivity, $K_{\mathrm{e}}$, was determined using a pair of Pt electrodes. Knowing the slope of the $E_{\mathrm{s}}$ vs $\Delta P$ dependence, the apparent electrokinetic potential of a substrate surface $\left(\zeta_{i}\right)$ was calculated from the Smoluchowski relationship

$$
\zeta_{i}=\frac{\eta K_{\mathrm{e}}}{\varepsilon}\left(\frac{\Delta E_{\mathrm{s}}}{\Delta P}\right)
$$

where $\eta$ is the dynamic viscosity of the solution, and $\varepsilon$ is the dielectric permittivity.

The correction for the surface conductivity contribution was introduced in a standard way, previously described in refs 50 and 61 . The correction was ca. $10 \%$ for ionic strength of $10^{-3}$ $\mathrm{M}$ and practically negligible for higher ionic strength.

Electrophoretic Mobility and the Dynamic Light-Scattering Measurements. A Malvern zetasizer nano ZS was used to determine the electrophoretic mobility and diffusion coefficients of PLL molecules in examined suspensions. The electrophoretic mobility of the polyelectrolyte was measured by the laser Doppler velocimetry technique (LDV), while a diffusion coefficient was determined using the dynamic light scattering (DLS).

All measurements were performed at $T=298 \mathrm{~K}$.

\section{THEORETICAL MODELING}

\subsection{Convective Diffusion Transport in the Impinging} Jet Cell. The experimental data derived from the reflectometry measurements were quantitatively interpreted in terms of a hybrid approach where the bulk transport is described by a phenomenological convective diffusion equation (see the Supporting Information) ${ }^{62}$

$$
\frac{\partial n}{\partial t}=D \nabla^{2} n-\frac{D}{k T} \nabla \cdot(\mathbf{F} n)-\mathbf{V} \cdot \nabla n
$$

where $n$ is the number concentration of macromolecules in the solution; $t$ is the time; $D$ is the net translation diffusion coefficient (averaged over all orientations); $k$ is the Boltzmann constant; $T$ is the absolute temperature; $\mathbf{F}$ is the external force 
vector; and $\mathbf{V}$ is the unperturbed (macroscopic) fluid velocity vector.

Equation 6 is coupled with the surface layer transport equation where the fluid convection effects are neglected ${ }^{63}$

$$
j_{\mathrm{a}}=\frac{1}{S_{\mathrm{g}}} \frac{d \Theta}{d t}=k_{\mathrm{a}} n\left(\delta_{\mathrm{a}}\right) B(\Theta)-\frac{k_{\mathrm{d}}}{S_{\mathrm{g}}} \Theta
$$

where $j_{\mathrm{a}}$ is the net adsorption/desorption flux; $S_{\mathrm{g}}$ is the characteristic cross-section of the macromolecule; $\Theta=S_{\mathrm{g}} N_{\mathrm{m}}$ is the absolute (dimensionless) coverage of macromolecules; $N_{\mathrm{m}}$ is their surface concentration; $k_{a}, k_{\mathrm{d}}$ are the kinetic adsorption and desorption constants; $n\left(\delta_{\mathrm{a}}\right)$ is the concentration of macromolecules at the adsorption boundary layer of the thickness $\delta_{\mathrm{a}}$; and $B(\Theta)$ is the generalized blocking function (referred more appropriately to as the available surface function).

Equation 7 is applied as the boundary condition for the bulk mass transfer equation; i.e., eq 6 is formulated for a given interface shape and flow pattern. Such a boundary value problem can be simplified for flows where the perpendicular velocity component does not depend on the position over the interface, e.g., for the impinging-jet flows in the region close to the stagnation point. ${ }^{62,64}$ In this case, the quasi-stationary bulk flux of particles $j_{\mathrm{b}}$ is given by the linear dependence

$$
j_{\mathrm{b}}=-D \frac{\partial n}{\partial z}=k_{\mathrm{c}}\left[n\left(\delta_{\mathrm{a}}\right)-n_{\mathrm{b}}\right]=j_{\mathrm{a}}
$$

where $z$ is the coordinate perpendicular to the interface; $n_{\mathrm{b}}$ is the number concentration in the bulk; and $k_{\mathrm{c}}$ is the bulk transfer rate constant known in analytical form for various flows and interface configurations. ${ }^{62,63}$ Combining eq 8 with eq 7 one obtains upon integration the following expression

$$
\int_{\Theta_{0}}^{\Theta} \frac{\left(k_{\mathrm{a}}-k_{\mathrm{c}}\right) B\left(\Theta^{\prime}\right)+k_{\mathrm{c}}}{k_{\mathrm{a}} k_{\mathrm{c}} S_{\mathrm{g}} n_{\mathrm{b}} B\left(\Theta^{\prime}\right)-k_{\mathrm{d}} k_{\mathrm{c}} \Theta^{\prime}} \mathrm{d} \Theta^{\prime}=t
$$

where $\Theta_{0}$ is the initial coverage of macromolecules.

In the case of the radial impinging jet flows, the mass transfer rate constant is given by the analytical expression ${ }^{64}$

$$
k_{\mathrm{c}}=0.776 \frac{\alpha_{\mathrm{r}}^{1 / 3} U_{\infty}^{1 / 3} D^{2 / 3}}{r_{\mathrm{b}}{ }^{2 / 3}}=0.530 \frac{\alpha_{\mathrm{r}}^{1 / 3} Q^{1 / 3} D^{2 / 3}}{r_{\mathrm{b}}{ }^{4 / 3}}
$$

where $\alpha_{\mathrm{r}}$ is the dimensionless parameter depending on the flow Reynolds number $R e ; U_{\infty}$ is the characteristic liquid velocity in the jet; $Q$ is the volumetric flow rate; and $r_{\mathrm{b}}$ is the radius of the jet (the inlet tubing, i.e., the bore hole).

Equation 10 is valid for the radial impinging-jet cell geometry matching the geometry of the cell used in our work. However, its precision is only satisfactory for the distance from the axis of symmetry below $0.1 r_{\mathrm{b}}$ (where $r_{\mathrm{b}}$ is the radius of the inlet tubing). At larger distances, this equation overestimates the mass transfer, but this effect was not quantitatively considered in previous works. ${ }^{42,57}$ In reality, the radius of the substrate area where the PLL adsorption is measured is comparable to $r_{\mathrm{b}}$, and in consequence the theoretical results calculated from eq 10 become markedly larger than that experimentally determined (as shown in Table 2).

In order to account for this deviation, a more accurate theoretical model derived in ref 62 and yielding eq 11, in which the dependence of the mass transfer rate on the distance from the cell center $x$ is considered in an exact way, is used in this work

$$
k_{\mathrm{c}}(\bar{x})=0.463 \frac{(\sin \bar{x})^{\pi / 2}}{\left[\int_{0}^{\bar{x}}(\sin y)^{(3 \pi / 2)-1} \mathrm{~d} y\right]^{1 / 3}} \frac{\alpha_{\mathrm{r}}^{1 / 3} U_{\infty}^{1 / 3} D^{2 / 3}}{r_{\mathrm{b}}^{2 / 3}}
$$

where $\bar{x}$ is the scaled tangential coordinate $\bar{x}=\pi r / 2 r_{\mathrm{b}}$, where $r$ is the distance from the symmetry line. Equation 11 is accurate for $\operatorname{Re}>4$ and $\bar{x}<\pi / 2$, i.e., $r<r_{\mathrm{b}}$.

As seen in Table 2, these exact theoretical results almost match experimental data.

3.2. Modeling PLL Molecule Adsorption Kinetics. Calculation of the adsorption kinetics from eq 7 requires, except for the mass transfer rate constant, the blocking function, which corresponds to the probability of the particle to adsorb on the interface at a given coverage $\Theta$. Accordingly, for $\Theta=0$, the blocking function is equal to unity, and for the maximum coverage, referred to for noninteracting particles as the jamming coverage, it becomes equal to zero, and thus the adsorption rate vanishes.

In this work, the PLL molecule adsorption is modeled applying the extended random sequential adsorption approach (referred to as soft-RSA) where the lateral electrostatic interactions among the adsorbing molecule with the molecules attached to the surface are considered. ${ }^{62}$ A rigid bead model is applied where the real molecule shape is approximated by a linear string of touching spheres of equal size. The diameter of the beads and their number in the chain are selected in order to match the data acquired in ref 31 using the molecular dynamic modeling and experimental measurements. Accordingly, the number of beads (equal to the elongation parameter) was equal to 122,68 , and 43 for ionic strength of $10^{-3}, 10^{-2}$, and $0.15 \mathrm{M}$, respectively (see Table S1, Supporting Information), whereas the molecule contour length was equal to 137,91 , and $67 \mathrm{~nm}$, respectively. The net interaction energy of the adsorbing molecule was calculated by summing up a pair of Yukawa (screened Coulomb) potentials among beads belonging to it and to molecules adsorbed within the interaction zone.

The primary result of this soft-RSA modeling is the dependence of the number of adsorbed molecules $N_{\mathrm{m}}$ on the dimensionless time $\tau$ defined as

$$
\tau=\frac{S_{\mathrm{g}}}{S_{i}} N_{\mathrm{att}}
$$

where $S_{\mathrm{g}}$ is the characteristic cross-section area of the molecule; $S_{i}$ is the surface area of the modeling domain; and $N_{\text {att }}$ is the number of adsorption attempts.

The maximum number of molecules adsorbed in a single run was typically equal to $5 \times 10^{3}$ after the maximum accessible time of $10^{5}$. In order to increase the precision of the modeling, ten independent runs were performed. This ensures the relative error of the calculations to be smaller than $0.5 \%$.

The absolute coverage of the macromolecules was calculated as

$$
\Theta=\frac{S_{\mathrm{g}}}{S_{i}} N_{\mathrm{m}}
$$

where $N_{\mathrm{m}}$ is the number of adsorbed molecules. 
Analogously, the mass coverage of the molecules, which is a parameter of a primary practical significance, is given by the formula

$$
\Gamma=\frac{M_{\mathrm{w}} N_{\mathrm{m}}}{A_{\mathrm{v}} S_{i}}=\frac{M_{\mathrm{w}}}{A_{\mathrm{v}} S_{\mathrm{g}}} \Theta
$$

where $M_{\mathrm{w}}$ is the molar mass of PLL and $A_{\mathrm{v}}$ is the Avogadro constant.

The primary kinetic runs derived from the soft-RSA modeling also enabled us to determine the blocking function exploiting the definition:

$$
B(\Theta)=\frac{d \Theta}{d \tau}
$$

The exact numerical data were fitted by logarithmic functions that allowed us to derive some useful analytical expressions for $B(\Theta)$. It is interesting to mention that in order to formulate these expressions the maximum coverage of molecules was not needed. Therefore, this form of the blocking function is particularly useful for evaluating the molecule adsorption kinetics from eq 9.

\section{RESULTS AND DISCUSSION}

\subsection{Bulk Characteristics of the PLL Molecule and} Silica Substrate. As mentioned, the diffusion coefficient (D) of PLL molecules was calculated from the dynamic light scattering (DLS) measurements for the ionic strength $10^{-3}-$ $0.15 \mathrm{M} \mathrm{NaCl}$ and $\mathrm{pH}$ 5.8. Knowing the diffusion coefficient, one can calculate the hydrodynamic diameter $d_{\mathrm{H}}$ of the molecules using the Stokes-Einstein relationship: ${ }^{60}$

$$
d_{\mathrm{H}}=\frac{k T}{3 \pi \eta D}
$$

The electrophoretic mobility of PLL molecules, denoted by $\mu_{\mathrm{e}}$, which is the parameter of a basic significance for characterizing the molecule-surface interactions, was directly measured by the LDV technique. Using the electrophoretic mobility, the electrokinetic potential of molecules was calculated using the Henry equation. ${ }^{65}$ Additionally, the experimental electrophoretic mobility value allows us to calculate the electrokinetic charge per polyelectrolyte molecule, $q$, from the Lorentz-Stokes relationship: ${ }^{60}$

$$
q=\frac{k T}{D} \mu_{\mathrm{e}}=3 \pi \eta d_{\mathrm{H}} \mu_{\mathrm{e}}
$$

Equation 17 can be directly used for calculations of the average number of elementary charges per molecule $N_{c}$

$$
N_{\mathrm{c}}=\frac{q}{e}=\frac{3 \pi \eta d_{\mathrm{H}} \mu_{\mathrm{e}}}{e}
$$

where $e=1.602 \times 10^{-19} \mathrm{C}$ is the elementary charge.

Consequently, the effective ionization degree $\alpha^{*}$ can be calculated from the formula

$$
\alpha^{*}=\frac{N_{\mathrm{c}}}{N_{\mathrm{T}}}
$$

where $N_{\mathrm{T}}$ equal to 584 is the average number of monomers in the PLL molecule. ${ }^{31,41}$

For the sake of convenience, the experimental values of the bulk physicochemical properties of PLL molecules consisting

\begin{tabular}{|c|c|}
\hline \multicolumn{2}{|l|}{ ionic strength $10^{-3} \mathrm{M}$, pH 5.8} \\
\hline diffusion coefficient $\left[\mathrm{cm}^{2} \mathrm{~s}^{-1}\right], D \times 10^{-7}$ & $1.9 \pm 0.4$ \\
\hline hydrodynamic diameter $[\mathrm{nm}], d_{\mathrm{H}}$ & $26 \pm 6$ \\
\hline electrophoretic mobility $\left[\mu \mathrm{m} \mathrm{cm}(\mathrm{V} \mathrm{s})^{-1}\right], \mu_{\mathrm{e}}$ & $3.7 \pm 0.2$ \\
\hline electrokinetic potentials $[\mathrm{mV}], \zeta$ & 70 \\
\hline number of electrokinetic charges, $N_{c}$ & 50 \\
\hline effective ionization degree, $\alpha^{*}$ & 0.085 \\
\hline geometrical cross-section area $\left[\mathrm{nm}^{2}\right], S_{\mathrm{g}}{ }^{31}$ & 153 \\
\hline \multicolumn{2}{|l|}{ ionic strength $10^{-2} \mathrm{M}, \mathrm{pH} 5.8$} \\
\hline diffusion coefficient $\left[\mathrm{cm}^{2} \mathrm{~s}^{-1}\right], D \times 10^{-7}$ & $2.0 \pm 0.3$ \\
\hline hydrodynamic diameter $[\mathrm{nm}], d_{\mathrm{H}}$ & $24 \pm 4$ \\
\hline electrophoretic mobility $\left[\mu \mathrm{m} \mathrm{cm}(\mathrm{V} \mathrm{s})^{-1}\right], \mu_{\mathrm{e}}$ & $3.5 \pm 0.2$ \\
\hline electrokinetic potentials $[\mathrm{mV}], \zeta$ & 63 \\
\hline number of electrokinetic charges, $N_{c}$ & 44 \\
\hline effective ionization degree, $\alpha^{*}$ & 0.076 \\
\hline geometrical cross-section area $\left[\mathrm{nm}^{2}\right], S_{\mathrm{g}}{ }^{31}$ & 121 \\
\hline \multicolumn{2}{|l|}{ ionic strength $0.15 \mathrm{M}, \mathrm{pH} 5.8$} \\
\hline diffusion coefficient $\left[\mathrm{cm}^{2} \mathrm{~s}^{-1}\right], D \times 10^{-7}$ & $2.2 \pm 0.3$ \\
\hline hydrodynamic diameter $[\mathrm{nm}], d_{\mathrm{H}}$ & $22 \pm 3$ \\
\hline electrophoretic mobility $\left[\mu \mathrm{m} \mathrm{cm}(\mathrm{V} \mathrm{s})^{-1}\right], \mu_{\mathrm{e}}$ & $2.1 \pm 0.2$ \\
\hline electrokinetic potentials $[\mathrm{mV}], \zeta$ & 40 \\
\hline number of electrokinetic charges, $N_{c}$ & 24 \\
\hline effective ionization degree, $\alpha^{*}$ & 0.041 \\
\hline geometrical cross-section area $\left[\mathrm{nm}^{2}\right], S_{\mathrm{g}}{ }^{31}$ & 102 \\
\hline
\end{tabular}
of diffusion coefficients, hydrodynamic diameter, electro- phoretic mobility, and electokinetic potentials obtained for various ionic strength and $\mathrm{pH} 5.8$ are collected in Table 1.

Table 1. Physicochemical Characteristics of PLL Molecules in Solutions $(T=298 \mathrm{~K})^{a}$

${ }^{a}$ PLL molar mass: $120 \mathrm{~kg} \mathrm{~mol}^{-1}$ determined by the intrinsic viscosity method. ${ }^{31}$

The electrokinetic potential of the $\mathrm{Si} / \mathrm{SiO}_{2}$ wafer, denoted by $\zeta_{i}$, was determined by conducting the streaming potential measurements according to the above-described procedure. The electrokinetic potentials determined at $\mathrm{pH} 5.8$ were equal to $-73 \pm 4,-55 \pm 5$, and $-41 \pm 6 \mathrm{mV}$ for ionic strength of $10^{-3} \mathrm{M}, 10^{-2} \mathrm{M}$, and $0.15 \mathrm{M}$, respectively.

4.2. Adsorption Kinetics of the PLL Molecule on the Silica Substrate. The adsorption kinetics of PLL at the water- $\mathrm{Si} / \mathrm{SiO}_{2}$ wafer interface was studied in situ by optical reflectometry. At first, the solid substrate, mounted in the impinging jet cell, was flushed with pure electrolyte solution of the same $\mathrm{pH}$ and ionic strength as a PLL solution. The reflectometry signal recorded during this stage represents the initial value $R(0)$ from eq 2 . Once the baseline was obtained, the input solution was switched to a PLL solution, and the deposition process was started. Initially, the adsorbed amount increased linearly, but after a few minutes, the adsorption plateau has been reached. After another $10 \mathrm{~min}$, the cell was flushed again, with pure electrolyte solution of the same $\mathrm{pH}$ and ionic strength as a PLL solution, to study the desorption process. Typical adsorption kinetics of the PLL molecule on the silica substrate are illustrated in Figure 1.

Figure 1A presents adsorption kinetics of PLL on the silica substrate for the same ionic strength $(0.15 \mathrm{M})$ but various PLL concentrations. While the value of the saturation plateau $\Gamma_{m x}$ remains constant, the time needed to reach the maximum adsorption value decreases with increasing PLL concentration. Figure 1B shows the opposite situation, where PLL concentration is fixed at $c_{\mathrm{b}}=5 \mathrm{mg} \mathrm{L}^{-1}$ but ionic strength is 

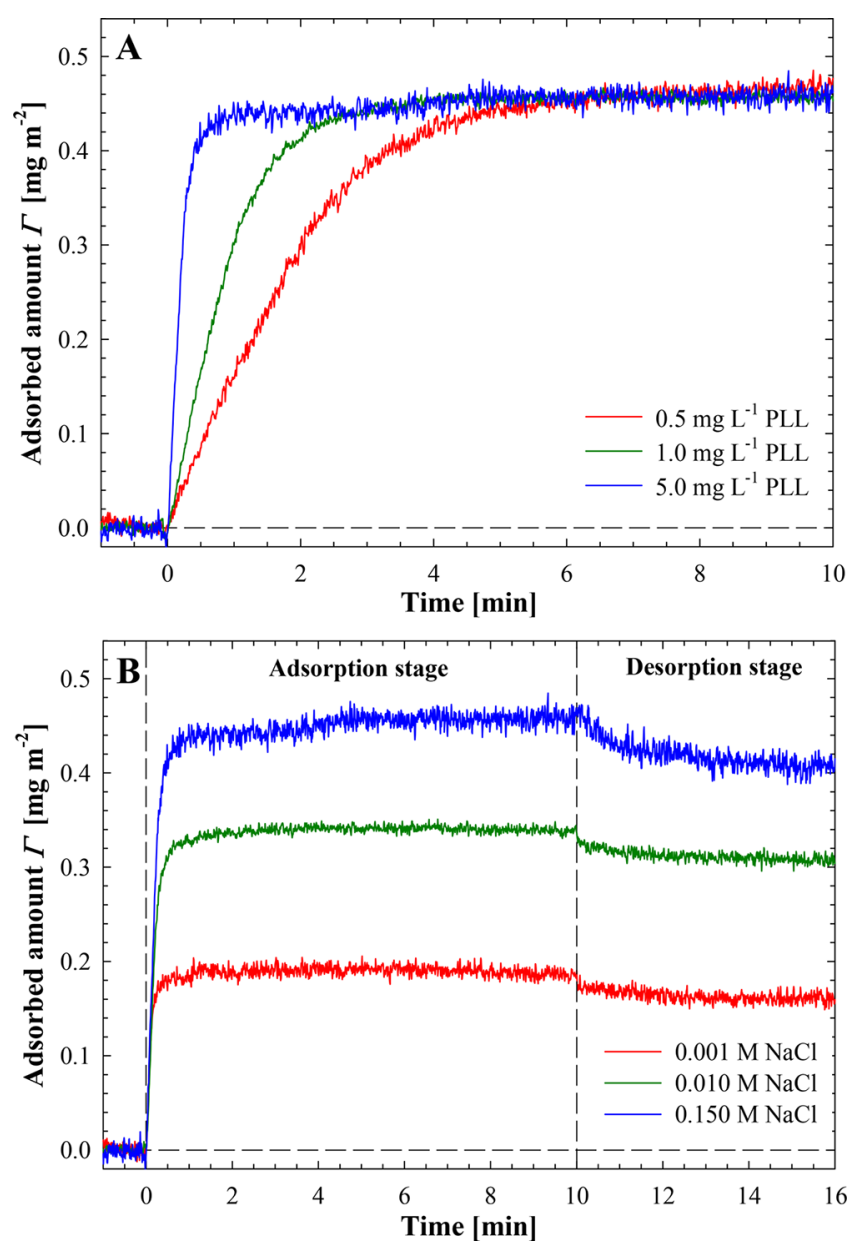

Figure 1. Primary kinetic runs for PLL molecule adsorption on the $\mathrm{Si} / \mathrm{SiO}_{2}$ surface determined by optical reflectivity measurements at $\mathrm{pH} 5.8$ and (A) $0.15 \mathrm{M}$ ionic strength, various PLL concentrations, and (B) $5 \mathrm{mg} \mathrm{L}^{-1}$ PLL concentration, various ionic strengths.

altered from $10^{-3}$ to $0.15 \mathrm{M}$. It is clearly seen that the maximum saturation value increases with increasing ionic strength.

The initial adsorption rate can be calculated from the slope of the linear function fitted to the initial part of the adsorption curve or by plotting the time derivative of the adsorption kinetics. In the latter case, the initial adsorption rate is reflected by a plateau in the derivative plot. ${ }^{42,66,67}$ As described in previous papers, ${ }^{42,66,67}$ the reliable values of initial adsorption rate can be estimated for the macroion bulk concentration below $10 \mathrm{mg} \mathrm{L}^{-1}$. This limitation is related to the problem of proper estimation of the plateau in the derivative plot, which in high concentrated solutions is short and masked by the finite dead time of the cell.

Figure 2 shows the initial adsorption rate $(d \Gamma / d t)_{t=0}$ plotted as a function of the PLL mass concentration $\left(c_{\mathrm{b}}\right)$ for $\mathrm{pH} 5.8$ and various ionic strengths. One can observe that at the initial stage the kinetic of adsorption can be described by the following relationship ${ }^{64,66}$

$$
\Gamma=k_{\mathrm{c}} c_{\mathrm{b}} t
$$

where $k_{\mathrm{c}}$ is the mass transfer rate constant that can be obtained from the slope of linear regression line fitting to the experimental data for short adsorption time.

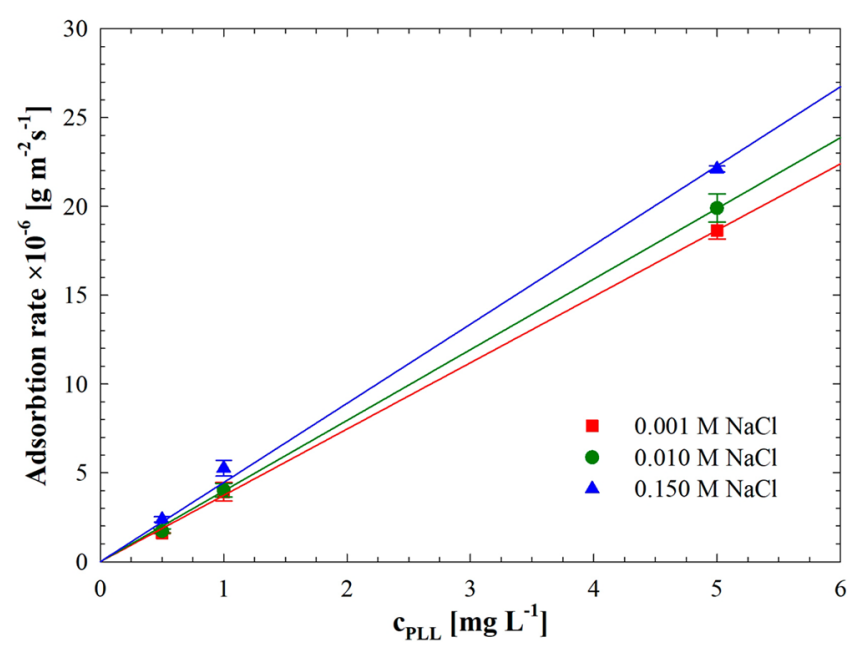

Figure 2. Initial adsorption rate as a function of the PLL concentration at $\mathrm{pH} 5.8$ and various ionic strengths. The solid line reflects the first-order kinetics with respect to the solution concentration.

It is also seen in Figure 2 that the increase in the ionic strength increased the initial adsorption rate of PLL molecules. This effect, in accordance to Table 2 and refs 41 and 42, can be

Table 2. Experimental and Theoretical Values of the Initial Mass Transfer Rate Constant

$\begin{array}{ccccc}I[\mathrm{M}] & \begin{array}{c}k_{\mathrm{c}}^{\exp \times 10^{-4}}\left[\mathrm{~cm} \mathrm{~s}^{-1}\right] \\ 10^{-3}\end{array} & \begin{array}{c}k_{\mathrm{c}}^{\text {theor }} \times 10^{-4} \\ {\left[\mathrm{~cm} \mathrm{~s}^{-1}\right] \text { eq } 10}\end{array} & \begin{array}{c}k_{\mathrm{c}}^{\text {theor }} \times 10^{-4} \\ {\left[\mathrm{~cm} \mathrm{~s}^{-1}\right] \text { eq } 11}\end{array} & \begin{array}{c}\beta[1] \\ \text { eq } 24\end{array} \\ 10^{-2} & 3.98 \pm 0.05 & 4.66 & 3.78 & 0.99 \\ 0.15 & 4.46 \pm 0.11 & 4.82 & 3.92 & 1.02 \\ & & 5.14 & 4.17 & 1.07\end{array}$

related to the changes in the conformation of the PLL molecule. An increase of the salt concentration the molecule attains a less elongated shape, which results in an increase in the diffusion coefficient.

Assuming the perfect sink conditions at the surface in the stagnation point flow geometry, ${ }^{64}$ the theoretical values of mass transfer rate constant can be calculated from eq 10 or by a numerical integration of eq 11 where it is considered that the collector radius $r_{\mathrm{b}}$ is equal to $0.4 \mathrm{~mm}$, which almost matches the maximum laser beam size $\left(r_{\text {beam }}<0.5 \mathrm{~mm}\right)$.

Table 2 collects all experimental $\left(k_{\mathrm{c}}^{\exp }\right)$ and theoretical $\left(k_{\mathrm{c}}^{\text {theor }}\right)$ values of the mass transfer rate constant, together with sticking coefficient $\beta$, defined as ${ }^{57}$

$$
\beta=\frac{k_{\mathrm{c}}^{\text {exp }}}{k_{\mathrm{c}}^{\text {theor }}}
$$

where $k_{\mathrm{c}}^{\text {theor }}$ is a theoretical mass transfer rate calculated using eq 11.

Figure 3A presents the adsorbed mass coverage at the saturation plateau as a function of $\mathrm{NaCl}$ concentration for $\mathrm{pH}$ 5.8 and various PLL bulk concentrations. As seen, the adsorbed mass is rather independent of the PLL bulk concentration in the studied range, i.e., $0.1-5 \mathrm{mg} \mathrm{L}^{-1}$. The observed increase of the plateau level with the ionic strength shows a similar trend to the previous study on PLL adsorption, $^{42}$ as well as to the studies on other polyelectrolytes. ${ }^{66-68}$ 

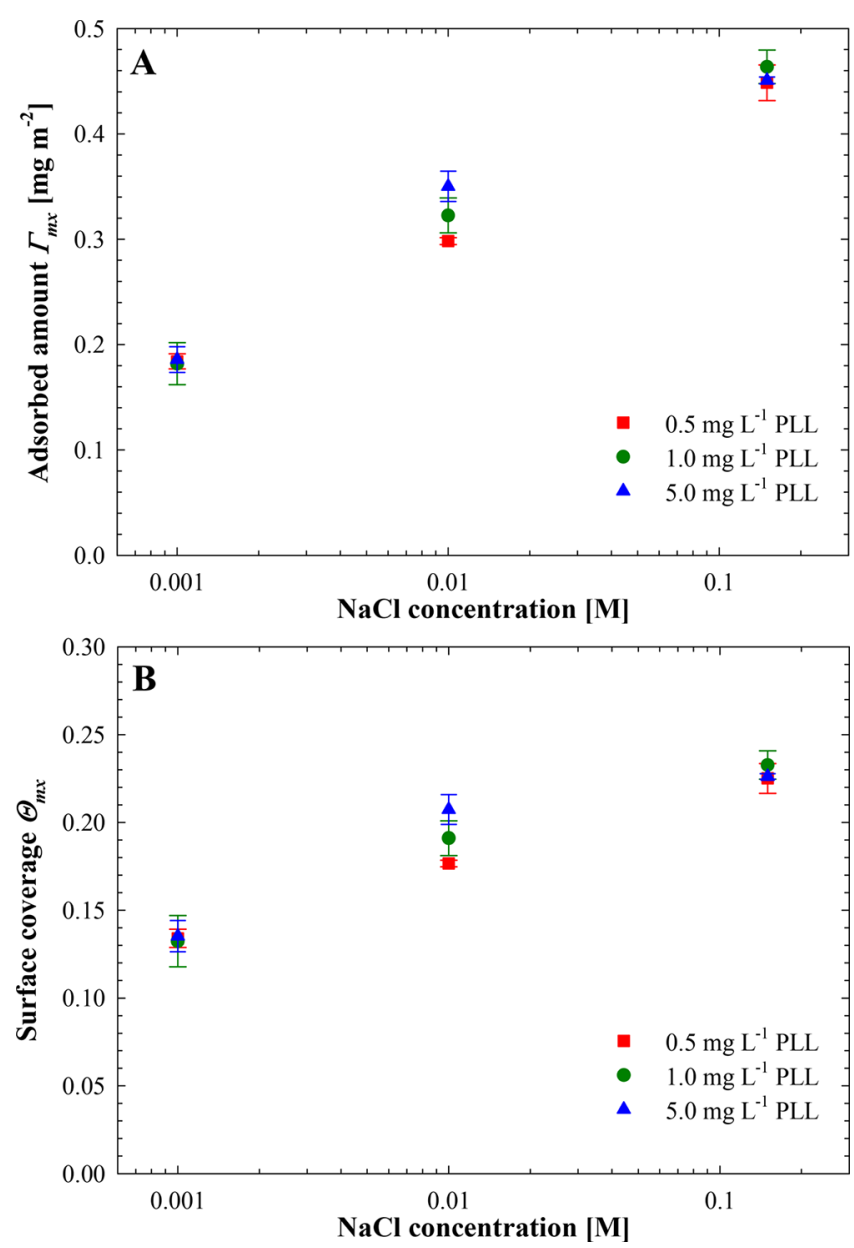

Figure 3. (A) Adsorbed mass and (B) surface coverage of PLL on Si/ $\mathrm{SiO}_{2}$ at the plateau for $\mathrm{pH} 5.8$ and various ionic strengths determined by optical reflectivity measurements.

Knowing $\Gamma_{\mathrm{m} x}$, one can also calculate the absolute surface coverage using the following formula

$$
\Theta_{\mathrm{m} x}=\frac{\Gamma_{\mathrm{m} x}}{M_{\mathrm{w}}} A_{\mathrm{v}} S_{\mathrm{g}}
$$

where $M_{\mathrm{w}}=120 \mathrm{~kg} \mathrm{~mol}^{-1}$ is the molar mass of $\mathrm{PLL}^{31}$ and $S_{\mathrm{g}}$ is a cross-section area of the PLL molecule (see Table 1). The calculated values of $\Theta_{\mathrm{m} x}$ are presented in Figure 3B.

4.3. Theoretical Interpretation of the PLL Adsorption Data. If the initial mass transfer rates are known one can calculate some derivative parameters, especially the mass transfer coupling constant $K$ (see Table 3 ), which is of basic significance for interpreting the adsorption kinetics of PLL molecules. As one can infer from the data shown in Table 3, the coupling constant assumes large values ranging between $3.2 \times 10^{3}$ and $2.0 \times 10^{3}$ for $I=10^{-3}$ and $0.15 \mathrm{M}$, respectively, meaning that for low coverage range the bulk transport should play a dominant role. Additionally, knowing the $K$ constant, one can define the dimensionless adsorption time, $\tau$, which is given by

$$
\tau=\frac{t}{t_{\mathrm{ch}}}=K S_{\mathrm{g}} k_{\mathrm{c}} n_{\mathrm{b}} t=K S_{\mathrm{g}} k_{\mathrm{c}} \frac{c_{\mathrm{b}}}{M_{\mathrm{w}}} A_{\mathrm{v}} t
$$

where $t_{\mathrm{ch}}=\frac{1}{K S_{\mathrm{g}} k_{\mathrm{c}} n_{\mathrm{b}}}$ is the characteristic time of the monolayer formation in the absence of blocking effects.

As shown in Table 3, the dimensionless time changes from $5.5 \times 10^{3}$ to $2.8 \times 10^{3}$ for $I=10^{-3}$ and $0.15 \mathrm{M}$, respectively (for the bulk PLL concentration of $1 \mathrm{mg} \mathrm{L}^{-1}$ and adsorption time of $600 \mathrm{~s}$ ). For the bulk PLL concentration of $5 \mathrm{mg} \mathrm{L}^{-1}$ one has $2.8 \times 10^{4}$ and $1.4 \times 10^{4}$ for $I=10^{-3}$ and $0.15 \mathrm{M}$, respectively.

It should be mentioned that the dimensionless experimental time defined by eq 23 corresponds to the dimensionless time defined in the soft-RSA modeling, which facilitates a direct comparison of the experimental and theoretical results. In Figure 4, snapshots of the PLL molecule monolayers obtained

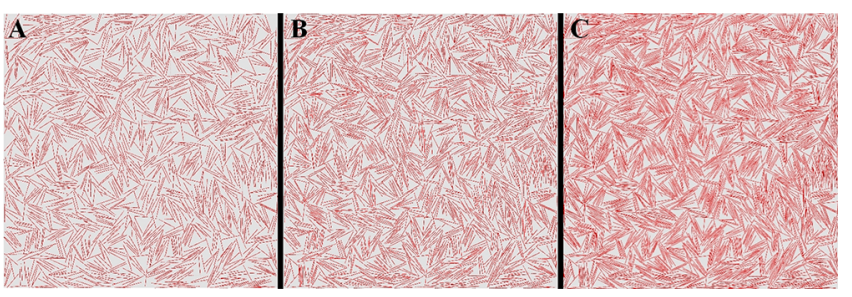

Figure 4. Snapshots of PLL molecule monolayers obtained for the rigid model for the dimensionless time $\tau$ equal to (A) 10, (B) 100 and (C) $10^{4}$, and the obtained surface concentration of adsorbed molecules was equal to (A) 1500 , (B) 2000 , and (C) $2600 \mu \mathrm{m}^{-2}$ for $I$ $=0.15 \mathrm{M}$. The dimensions of the interface are equal to $1 \times 1 \mu \mathrm{m}$.

from the modeling for various values of adsorption time $\tau$ are presented for $I=0.15 \mathrm{M}$. Qualitatively, one can notice that the surface concentration of the monolayer very slowly increases with the adsorption time, attaining 2000 and $2600 \mu \mathrm{m}^{-2}$ for $\tau$ $=10^{2}$ and $10^{4}$, respectively. This corresponds to the dimensional coverage calculated from eq 22 equal to 0.40 and $0.52 \mathrm{mg} \mathrm{m}^{-2}$. It is also shown in the Supporting Information that for $\tau>10^{2}$ the adsorption kinetics derived from modeling can be well fitted by the following formula:

Table 3. Physicochemical Parameters Used in the Soft-RSA Modeling of PLL Adsorption and the Interpretation of

\begin{tabular}{|c|c|c|c|c|c|c|c|c|}
\hline$I[\mathrm{M}]$ & $D \times 10^{-7}\left[\mathrm{~cm}^{2} \mathrm{~s}^{-1}\right]$ & $d_{\mathrm{c}}[\mathrm{nm}]$ & $S_{\mathrm{g}}\left[\mathrm{nm}^{2}\right]$ & $k_{\mathrm{c}} \times 10^{-4}\left[\mathrm{~cm} \mathrm{~s}^{-1}\right]$ & $k_{\mathrm{a}}\left[\mathrm{cm} \mathrm{s}^{-1}\right]$ & $K \times 10^{3}[1]$ & $\tau_{1} \times 10^{3}[1]$ & $\tau_{5} \times 10^{4}[1]$ \\
\hline $10^{-3}$ & 1.9 & 1.12 & 153 & 3.7 & 1.2 & 3.2 & 5.5 & 2.8 \\
\hline $10^{-2}$ & 2.0 & 1.33 & 121 & 4.0 & 1.0 & 2.5 & 3.6 & 1.8 \\
\hline 0.15 & 2.2 & 1.55 & 102 & 4.5 & 0.9 & 2.0 & 2.8 & 1.4 \\
\hline
\end{tabular}
Experimental Data $\left(\mathrm{pH} \mathrm{5.8,} k_{\mathrm{d}}=0, T=298 \mathrm{~K}\right)^{a}$

${ }^{a} S_{\mathrm{g}}=d_{\mathrm{c}} L_{\mathrm{c}}$, geometrical cross section area; ${ }^{31} d_{\mathrm{c}}$, chain diameter; ${ }^{31} L_{\mathrm{c}}$ contour length; ${ }^{31} k_{\mathrm{a}}=\frac{D}{\delta_{\mathrm{a}}} \frac{1}{\left[1+\frac{1}{2} \ln \frac{\delta_{\mathrm{a}}}{\delta_{\mathrm{m}}}\right]} ; \delta_{\mathrm{a}}=d_{\mathrm{c}} ; \delta_{\mathrm{m}}=0.5$ nm; $K=k_{\mathrm{a}} / k_{\mathrm{c}} ;$ $\tau=10^{-6} S_{\mathrm{g}} k_{\mathrm{a}} \frac{c_{\mathrm{b}}}{M_{\mathrm{w}}} A_{\mathrm{v}} t_{\mathrm{m} x} ; t_{\mathrm{m} x}=600 \mathrm{~s}$; for $\tau_{1}: c_{\mathrm{b}}=1 \mathrm{mg} \mathrm{L}^{-1}$; for $\tau_{5}: c_{\mathrm{b}}=5 \mathrm{mg} \mathrm{L}^{-1}$. 


$$
\begin{aligned}
\Theta & =0.340+0.0214 \ln (\tau) \\
& =0.340+0.0214 \ln \left(K S_{\mathrm{g}} k_{\mathrm{c}} \frac{c_{\mathrm{b}}}{M_{\mathrm{w}}} A_{\mathrm{v}} t\right)
\end{aligned}
$$

This equation unequivocally indicates that the maximum coverage predicted for hard particles, which is equal to 0.77 , could be attained after the time $\tau$ of ca. $1 \times 10^{9}$. This corresponds to the dimensional adsorption time (for the $1 \mathrm{mg}$ $\mathrm{L}^{-1}$ bulk concentration of PLL) of $2 \times 10^{8} \mathrm{~s}$ (6.5 years), which is clearly inaccessible from an experimental point of view. In consequence, the plateau values shown in Figure 3 should only be treated as kinetically determined rather than the absolute maximum coverages. It seems that this conclusion is important for the interpretation of isotherms reported in macroion adsorption studies ${ }^{42,66,69}$ because the observed increase in the maximum coverage with the bulk concentration of a solute may be due to the kinetic limitations rather than to the reversibility of the adsorption.

This effect becomes even more pronounced for lower ionic strengths where the prelogarithmic factors in eq 24 were equal to 0.012 and 0.019 for $I=10^{-3}$ and $10^{-2} \mathrm{M}$, respectively. The corresponding monolayers derived from the soft-RSA modeling for $\tau$ equal to $1 \times 10^{4}$ are presented in Figure 5. Another

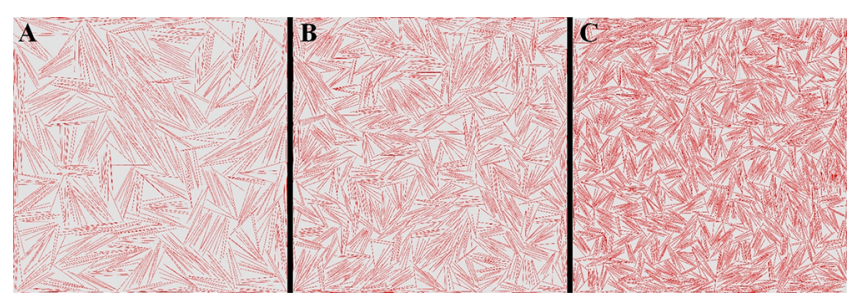

Figure 5. Snapshots of PLL molecule monolayers obtained for the rigid model, the dimensionless time $\tau$ equal to $10^{4}$ : (A) $I=10^{-3} \mathrm{M}$, (B) $I=10^{-2} \mathrm{M}$, and (C) $I=0.15 \mathrm{M}$. The surface concentration of adsorbed molecules was equal to (A) 800, (B) 1400, and (C) 2600 $\mu \mathrm{m}^{-2}$. The dimensions of the interface are equal to $1 \times 1 \mu \mathrm{m}$.

interesting feature observed in the monolayer shown in Figures 4 and 5 for the long adsorption time is a well-pronounced tendency to form local structures of parallel oriented molecules quite analogous to a $2 \mathrm{D}$ liquid crystal behavior.

The theoretical data obtained from soft-RSA modeling are compared in Table 4 with the experimental plateau values of the PLL molecule coverage derived from the reflectometry (see Figure 3). One can observe that the agreement between both results is satisfactory, confirming a significant role of ionic strength, which governs the range of the electrostatic interactions. The electrostatic forces influence not only lateral

Table 4. Plateau Values of the PLL Coverage Obtained from Experiments and from the Soft-RSA Modeling ${ }^{a}$

\begin{tabular}{cccc}
\multicolumn{3}{c}{ adsorbed amount $\Gamma\left[\mathrm{mg} \mathrm{m}^{-2}\right]$} \\
\cline { 2 - 4 }$I[\mathrm{M}]$ & optical reflectometry & soft-RSA & $\mathrm{RSA}^{b}$ \\
$10^{-3}$ & $0.18 \pm 0.02$ & $0.15-0.17$ & 0.42 \\
$10^{-2}$ & $0.33 \pm 0.02$ & $0.27-0.30$ & 0.60 \\
0.15 & $0.45 \pm 0.02$ & $0.50-0.54$ & 0.77
\end{tabular}

${ }^{a^{a}}$ The experimental values were determined for the bulk PLL concentration varying between 0.5 and $5 \mathrm{mg} \mathrm{L}^{-1}$, respectively. ${ }^{b}$ Maximum coverage for hard (noninteracting) molecules calculated from eq S14. interactions among adsorbing and adsorbed molecules but also the conformation of the molecule, which becomes more extended for lower ionic strength. Because both these effects act in the same direction, their net result is a considerable decrease in the mass coverage for lower ionic strength after experimentally accessible adsorption time (see Table 4).

The utility of the soft-RSA modeling was also checked, comparing the experimental kinetic runs with theoretical predictions calculated from eq 9, assuming the irreversible adsorption regime and using the appropriate blocking functions described by eq S23. As seen in Figure 6, the

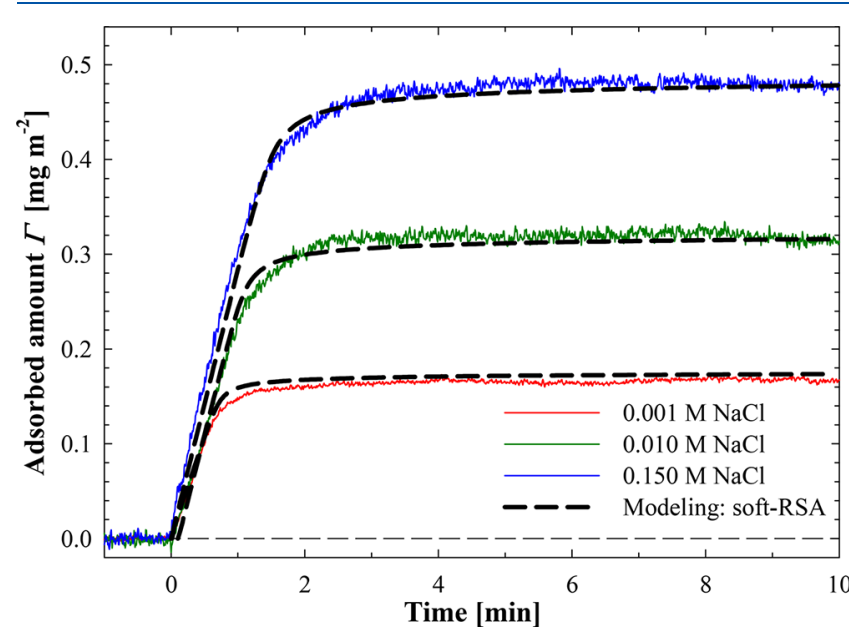

Figure 6. Kinetics of PLL adsorption on the $\mathrm{Si} / \mathrm{SiO}_{2}$ surface determined by optical reflectivity measurements. The solid lines represent the experimental results determined for $\mathrm{pH}$ 5.8, PLL bulk concentration $c_{\mathrm{b}}=1 \mathrm{mg} \mathrm{L}^{-1}$, volumetric flow rate $Q=1.02 \mathrm{~cm}^{3} \mathrm{~min}^{-1}$, and various ionic strengths. The dashed line denotes the theoretical calculations derived from the soft-RSA model.

theoretical results adequately describe experimental kinetic runs for various ionic strengths. It is also confirmed that for the short adsorption time the PLL coverage linearly increases, which confirms the bulk transport controlled regime. This is physically due to the fact that the transport through the adsorption layer, because of its low thickness (about $1 \mathrm{~nm}$ ), is much faster than through the diffusion boundary layer in the bulk that extends over the distance of $3-5 \times 10^{3} \mathrm{~nm}$. Accordingly, the linear adsorption regime can be described by eq 20.

4.4. Electrokinetic Characteristic of the PLL Monolayer. PLL layers on the $\mathrm{Si} / \mathrm{SiO}_{2}$ substrate were thoroughly characterized in situ using the streaming potential method. This method was used not only to acquire the electrokinetic potential of PLL-covered silica but also to determine the maximum coverage of PLL on modified surfaces. The experimental procedure was as follows: first, the adsorption PLL molecule was carried out in situ in the cell under convection-controlled transport (fixed flow rate) at $\mathrm{pH} 5.8$ and fixed ionic strength equal to $10^{-3}, 10^{-2}$, and $0.15 \mathrm{M}$, respectively. The coverage of the adsorbed layer was regulated varying the bulk macroion concentration $\left(1-5 \mathrm{mg} \mathrm{L}^{-1}\right)$ and the adsorption time $(5-60 \mathrm{~min})$. Afterward, the cell was washed with pure electrolyte, and the streaming potential measurements were carried out for ionic strengths equal to $10^{-2} \mathrm{M} \mathrm{NaCl}$. The electrokinetic potential was calculated using the Smoluchowski equation. The primary dependencies of the electrokinetic potential on the adsorption time were converted 
to the dependence of the electrokinetic potential on the absolute layer coverage exploiting eq 20 which was transformed to

$$
\Theta=k_{\mathrm{c}} \frac{c_{\mathrm{b}}}{M_{\mathrm{w}}} A_{\mathrm{v}} S_{\mathrm{g}} t
$$

where $k_{\mathrm{c}}$ is the mass transfer rate constant for the streaming potential cell (in the form of a parallel-plate channel) calculated from the formula ${ }^{62}$

$$
k_{\mathrm{c}}=0.9247 \frac{Q^{1 / 3} D^{2 / 3}}{b_{\mathrm{c}}^{2 / 3} c_{\mathrm{c}}^{1 / 3} L_{\mathrm{c}}^{1 / 3}}
$$

where $Q$ is the volumetric flow rate in the channel, $2 b_{c}, c_{c}$, and $L_{\mathrm{c}}$ are the cell thickness, the width, and the length, respectively.

The experimental results obtained in this way are presented in Figure 7 as the dependence of the zeta potential of the silica

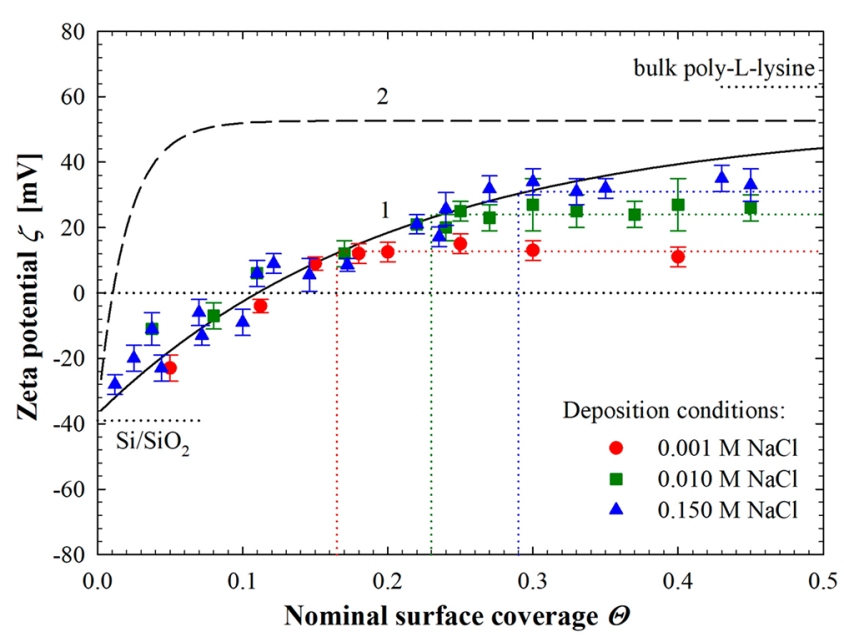

Figure 7. Dependence of the zeta potential of the $\mathrm{Si} / \mathrm{SiO}_{2}$ substrate on the nominal PLL coverage obtained from the streaming potential measurements. Measurement conditions: $I=10^{-2} \mathrm{M}$, pH 5.8. The solid line (1) shows the theoretical results calculated using the electrokinetic model for the side-on adsorption of PLL molecules, ${ }^{41}$ and the dashed line (2) shows the theoretical results obtained for the unoriented adsorption regime.

substrate on the nominal coverage of PLL. One can observe that the negative electrokinetic potential of the silica surface monotonically increases with PLL coverage that leads to the inversion in sign to positive at $\Theta=0.10$. Afterward, the electrokinetic potential attains positive plateau values equal to $30 \pm 5,25 \pm 5$, and $10 \pm 3 \mathrm{mV}$ for the PLL adsorption conditions of $0.15,10^{-2}$, and $10^{-3} \mathrm{M}$, respectively. The adsorption of PLL molecules on surfaces exhibiting positive zeta potential (where the initial negative zeta potential of the substrate reverses its sign) is a rather unusual phenomenon although often met in macroion adsorption studies. This effect is physically due to the largely nonuniform (heterogeneous) charge distribution over the substrate caused by PLL adsorption. One should remember that at the zeta potential inversion point only ca. $10 \%$ of the surface is covered, exhibiting a positive net charge, whereas the remaining $90 \%$ still remains negatively charged in the microscale, enabling additional PLL molecule adsorption. Hence, the results shown in Figure 7 directly confirm that the mean-field theory using the macroscopically average value of the zeta potential is not appropriate for describing macroion adsorption phenomena. In this case only the approach based on the direct calculation of the interactions among discrete charges, which was applied in our work, can yield meaningful results.

Moreover, it is interesting to mention that the largest value of $30 \mathrm{mV}$ is still markedly lower than the bulk electrokinetic potential of the PLL molecules $\zeta_{\mathrm{p}}$ equal to $65 \mathrm{mV}$ for $10^{-2} \mathrm{M}$. These experimental results were theoretically interpreted in terms of the electrokinetic model discussed in refs 52 and 53 . In this model, it is considered that the macromolecules adsorbed on homogeneous interfaces modify the electric potential distribution and the macroscopic shearing flow. As a result, an additional contribution to the streaming potential appears that originates from the double-layer region adjacent to the adsorbed macromolecules. Another effect appears because the adsorbing macromolecules decrease the ambient flow at the interface over distances significantly exceeding their dimensions. This decreases the streaming current contribution stemming from the interface and in consequence the absolute value of the streaming potential.

One can observe in Figure 7 that the experimental data are well reflected by the electrokinetic model, assuming that PLL adsorption occurs in the side-on (flat) orientation (solid line in Figure 7). In contrast, the theoretical results were calculated assuming an unoriented adsorption of PLL molecules (dashed line in Figure 7) significantly overestimates the experimental data.

The plateau values of the electrokinetic potential allow us to calculate the maximum coverage of PLL on the silica substrate using the formula ${ }^{60}$

$$
\Theta=\frac{1}{C_{i}^{0}} \ln \frac{\zeta_{i}-\zeta_{\mathrm{p}} / \sqrt{2}}{\zeta-\zeta_{\mathrm{p}} / \sqrt{2}}
$$

where $\zeta_{i}$ is the electrokinetic potential of the uncovered silica surface; $\zeta_{\mathrm{p}}$ is the electrokinetic potential of PLL molecules in the bulk; and $C_{i}^{0}$ is the dimensionless constant numerically calculated for various shapes of molecules. ${ }^{53}$

The values of $\Theta$ calculated from eq 27 and $\Gamma$ calculated from eq 14 are compared in Table 5 with the soft-RSA theoretical

Table 5. Maximum Coverages Obtained from the Streaming Potential Measurements and from the Soft-RSA Modeling

\begin{tabular}{ccccc} 
& \multicolumn{2}{c}{ streaming potential } & & soft-RSA \\
\cline { 2 - 3 }$I[\mathrm{M}]$ & $\Theta[1]$ & $\Gamma\left[\mathrm{mg} \mathrm{m}^{-2}\right]$ & & $\Gamma\left[\mathrm{mg} \mathrm{m}^{-2}\right]$ \\
$10^{-3}$ & $0.16 \pm 0.02$ & $0.21 \pm 0.02$ & & $0.15-0.17$ \\
$10^{-2}$ & $0.22 \pm 0.05$ & $0.36 \pm 0.08$ & & $0.27-0.30$ \\
0.15 & $0.29 \pm 0.03$ & $0.57 \pm 0.06$ & & $0.50-0.54$ \\
\hline
\end{tabular}

data. One can observe that the agreement is quite satisfactory, especially for ionic strength of $0.15 \mathrm{M}$, which confirms the utility of the streaming potential method for determining the orientation of adsorbed macroion molecules and their coverage.

\section{CONCLUSIONS}

The kinetics of PLL adsorption on silica for various ionic strengths was determined in situ under controlled flow conditions using the optical reflectometry and the streaming potential methods. Precise measurements of the initial adsorption rates enabled us to determine the mass transfer rate constants, which were adequately interpreted in terms of the convective diffusion theory. Moreover, the dependence of 
the adsorption rate on the radial coordinate in the impingingjet cell was considered in an exact way.

The kinetic runs also confirmed an irreversible adsorption mechanism of PLL on silica. These experimental results were quantitatively interpreted in terms of the theoretical data derived from the random sequential adsorption modeling based on the coarse-grained Monte Carlo approach. A significant improvement of our approach in comparison with previous literature reports $35,38,40,42$ is that the physicochemical parameters characterizing the PLL molecule, especially their shape and dimensions, were considered. Also, the electrostatic interactions among adsorbing and adsorbed molecules were considered, which enabled us to perform an $a b$ initio type modeling of PLL adsorption kinetics. This unique combination of experimental measurements and theoretical modeling furnished a new insight into the mechanism of macroion adsorption controlled by electrostatic interactions, affecting both the molecule conformations and the blocking effects. In consequence, the plateau values of the PLL coverage observed in the kinetic runs are controlled by kinetic rather than by the thermodynamic effects. This conclusion may be important for the interpretation of isotherms reported in macroion adsorption studies because the increase in the maximum coverage with the bulk concentration of a solute can be due to the kinetic limitations rather than to the reversibility of the adsorption.

It is also worth mentioning that the experimental results derived from reflectometry agree with the streaming potential results, where one can monitor in situ the zeta potential of PLL layers and in consequence the adsorption/desorption kinetics.

Besides significance for basic science, the results obtained in this work can be exploited for developing reliable procedures of preparing stable PLL monolayers of well-controlled coverage and electrokinetic properties.

\section{ASSOCIATED CONTENT}

\section{SI Supporting Information}

The Supporting Information is available free of charge at https://pubs.acs.org/doi/10.1021/acs.jpcc.9b10870.

Modeling of polyelectrolyte adsorption kinetics using the soft-RSA approach (PDF)

\section{AUTHOR INFORMATION}

\section{Corresponding Authors}

Maria Morga - Jerzy Haber Institute of Catalysis and Surface Chemistry, Polish Academy of Sciences, 30-239 Krakow,

Poland; 10 orcid.org/0000-0002-4913-9244;

Email: ncmorga@cyf-kr.edu.pl

Zbigniew Adamczyk - Jerzy Haber Institute of Catalysis and Surface Chemistry, Polish Academy of Sciences, 30-239 Krakow, Poland; (1) orcid.org/0000-0002-8358-3656;

Email: ncadamcz@cyf-kr.edu.pl

\section{Authors}

Dominik Kosior - Department of Inorganic and Analytical Chemistry, University of Geneva, 1205 Geneva, Switzerland

Plinio Maroni - Department of Inorganic and Analytical Chemistry, University of Geneva, 1205 Geneva, Switzerland

Michał Cieśla - Jagiellonian University, Faculty of Physics, Astronomy, and Applied Computer Science, 30-348 Krakow, Poland; (1) orcid.org/0000-0002-1191-0718

Complete contact information is available at: https://pubs.acs.org/10.1021/acs.jpcc.9b10870

\section{Notes}

The authors declare no competing financial interest.

\section{ACKNOWLEDGMENTS}

This work was financially supported by the National Science Centre Research: Sonata Project UMO 2015/17/D/ST4/ 00569 (streaming potential measurements and quantitative analysis of PLL adsorption at solid/liquid interfaces), by Opus Project UMO 2015/19/B/ST5/00847 (theoretical description of macroion adsorption), and by the University of Geneva (optical reflectometry measurements).

\section{REFERENCES}

(1) Decher, G. Fuzzy Nanoassemblies: Toward Layered Polymeric Multicomposites. Science 1997, 277 (5330), 1232-1237.

(2) Zhao, Y.; Sakai, F.; Su, L.; Liu, Y.; Wei, K.; Chen, G.; Jiang, M. Progressive Macromolecular Self-Assembly: From Biomimetic Chemistry to Bio-Inspired Materials. Adv. Mater. 2013, 25 (37), 52155256.

(3) Richardson, J. J.; Björnmalm, M.; Caruso, F. Technology-Driven Layer-by-Layer Assembly of Nanofilms. Science 2015, 348 (6233), aaa2491.

(4) Morga, M.; Adamczyk, Z.; Gödrich, S.; Ócwieja, M.; Papastavrou, G. Monolayers of Poly-l-Lysine on Mica - Electrokinetic Characteristics. J. Colloid Interface Sci. 2015, 456, 116-124.

(5) Furusawa, K.; Kanesaka, M.; Yamashita, S. Adsorption Behavior of Poly-l-Lysine and Its Conformation at the Latex-Water Interface. J. Colloid Interface Sci. 1984, 99 (2), 341-348.

(6) Furst, E. M.; Pagac, E. S.; Tilton, R. D. Coadsorption of Polylysine and the Cationic Surfactant Cetyltrimethylammonium Bromide on Silica. Ind. Eng. Chem. Res. 1996, 35 (5), 1566-1574.

(7) Orive, G.; Tam, S. K.; Pedraz, J. L.; Hallé, J.-P. Biocompatibility of Alginate-Poly-l-Lysine Microcapsules for Cell Therapy. Biomaterials 2006, 27 (20), 3691-3700.

(8) Shan, C.; Yang, H.; Han, D.; Zhang, Q.; Ivaska, A.; Niu, L. Water-Soluble Graphene Covalently Functionalized by Biocompatible Poly-l-Lysine. Langmuir 2009, 25 (20), 12030-12033.

(9) Mazia, D.; Schatten, G.; Sale, W. Adhesion of Cells to Surfaces Coated with Polylysine. Applications to Electron Microscopy. J. Cell Biol. 1975, 66 (1), 198-200.

(10) Frey, B. L.; Jordan, C. E.; Kornguth, S.; Corn, R. M. Control of the Specific Adsorption of Proteins onto Gold Surfaces with Poly(LLysine) Monolayers. Anal. Chem. 1995, 67 (24), 4452-4457.

(11) Muzzio, N. E.; Pasquale, M. A.; Rios, X.; Azzaroni, O.; Llop, J.; Moya, S. E. Adsorption and Exchangeability of Fibronectin and Serum Albumin Protein Corona on Annealed Polyelectrolyte Multilayers and Their Consequences on Cell Adhesion. Adv. Mater. Interfaces 2019, 6 (8), 1900008.

(12) Krikstolaityte, V.; Hamit-Eminovski, J.; Abariute, L.; Niaura, G.; Meskys, R.; Arnebrant, T.; Lisak, G.; Ruzgas, T. Impact of Molecular Linker Size on Physicochemical Properties of Assembled Gold Nanoparticle Mono-/Multi-Layers and Their Applicability for Functional Binding of Biomolecules. J. Colloid Interface Sci. 2019, 543, 307-316.

(13) Kranz, B. R.; Thiel, E.; Thierfelder, S. Immunocytochemical Identification of Meningeal Leukemia and Lymphoma: Poly-L-LysineCoated Slides Permit Multimarker Analysis Even with Minute Cerebrospinal Fluid Cell Specimens. Blood 1989, 73 (7), 1942-1950.

(14) Barrantes, A.; Wengenroth, J.; Arnebrant, T.; Haugen, H. J. Poly-l-Lysine/Heparin Multilayer Coatings Prevent Blood Protein Adsorption. J. Colloid Interface Sci. 2017, 485, 288-295.

(15) Zhao, Y.; Zhang, Y.-H.; Zhuge, Z.; Tang, Y.-H.; Tao, J.-W.; Chen, Y. Synthesis of a Poly-l-Lysine/Black Phosphorus Hybrid for Biosensors. Anal. Chem. 2018, 90 (5), 3149-3155. 
(16) Ghilini, F.; González, M. C. R.; Miñán, A. G.; Pissinis, D.; Creus, A. H.; Salvarezza, R. C.; Schilardi, P. L. Highly Stabilized Nanoparticles on Poly-l-Lysine-Coated Oxidized Metals: A Versatile Platform with Enhanced Antimicrobial Activity. ACS Appl. Mater. Interfaces 2018, 10 (28), 23657-23666.

(17) Wu, C.; Sun, J.; Lu, Y.; Wu, T.; Pang, J.; Hu, Y. In Situ SelfAssembly Chitosan $/ \varepsilon$-Polylysine Bionanocomposite Film with Enhanced Antimicrobial Properties for Food Packaging. Int. J. Biol. Macromol. 2019, 132, 385-392.

(18) Yu, H.; Liu, L.; Li, X.; Zhou, R.; Yan, S.; Li, C.; Luan, S.; Yin, J.; Shi, H. Fabrication of Polylysine Based Antibacterial Coating for Catheters by Facile Electrostatic Interaction. Chem. Eng. J. 2019, 360, 1030-1041.

(19) Ryser, H. J.-P.; Shen, W.-C. Conjugation of Methotrexate to Poly(L-Lysine) Increases Drug Transport and Overcomes Drug Resistance in Cultured Cells. Proc. Natl. Acad. Sci. U. S. A. 1978, 75 (8), 3867-3870.

(20) Zauner, W.; Ogris, M.; Wagner, E. Polylysine-Based Transfection Systems Utilizing Receptor-Mediated Delivery. Adv. Drug Delivery Rev. 1998, 30 (1), 97-113.

(21) Hartono, S. B.; Gu, W.; Kleitz, F.; Liu, J.; He, L.; Middelberg, A. P. J.; Yu, C.; Lu, G. Q.; Qiao, S. Z. Poly-l-Lysine Functionalized Large Pore Cubic Mesostructured Silica Nanoparticles as Biocompatible Carriers for Gene Delivery. ACS Nano 2012, 6 (3), 2104-2117.

(22) Babič, M.; Horák, D.; Trchová, M.; Jendelová, P.; Glogarová, K.; Lesný, P.; Herynek, V.; Hájek, M.; Syková, E. Poly(l-Lysine)Modified Iron Oxide Nanoparticles for Stem Cell Labeling. Bioconjugate Chem. 2008, 19 (3), 740-750.

(23) Borri, C.; Centi, S.; Ratto, F.; Pini, R. Polylysine as a Functional Biopolymer to Couple Gold Nanorods to Tumor-Tropic Cells. J. Nanobiotechnol. 2018, 16 (1), 50.

(24) Xu, T.; Chi, B.; Chu, M.; Zhang, Q.; Zhan, S.; Shi, R.; Xu, H.; Mao, C. Hemocompatible $\varepsilon$-Polylysine-Heparin Microparticles: A Platform for Detecting Triglycerides in Whole Blood. Biosens. Bioelectron. 2018, 99, 571-577.

(25) Davidson, B.; Fasman, G. D. The Conformational Transitions of Uncharged Poly-L-Lysine. $\alpha$ Helix-Random Coil- $\beta$ Structure. Biochemistry 1967, 6 (6), 1616-1629.

(26) Lee, W. I.; Schurr, J. M. Dynamic light scattering studies of poly-L-lysine $\mathrm{HBr}$ in the presence of added salt. Biopolymers 1974, 13 (5), 903-908.

(27) Satake, I.; Yang, J. T. Effect of Temperature and PH on the $\beta-$ Helix Transition of Poly(L-Lysine) in Sodium Dodecyl Sulfate Solution. Biopolymers 1975, 14 (9), 1841-1846.

(28) Wilcoxon, J. P.; Schurr, J. M. Electrophoretic Light Scattering Studies of Poly(L-lysine) in the Ordinary and Extraordinary Phase. Effects of Salt, Molecular Weight, and Polyion Concentration. J. Chem. Phys. 1983, 78 (6), 3354-3364.

(29) Nemoto, N.; Matsuda, H.; Tsunashima, Y.; Kurata, M. Dynamic Light Scattering of Poly(L-Lysine) Hydrobromide in Aqueous Solutions. Macromolecules 1984, 17 (9), 1731-1735.

(30) Rodríguez-Maldonado, L.; Fernández-Nieves, A.; FernándezBarbero, A. Dynamic Light Scattering from High Molecular Weight Poly-1-Lysine Molecules. Colloids Surf., A 2005, 270-271, 335-339.

(31) Adamczyk, Z.; Morga, M.; Kosior, D.; Batys, P. Conformations of Poly-l-Lysine Molecules in Electrolyte Solutions: Modeling and Experimental Measurements. J. Phys. Chem. C 2018, 122 (40), 23180-23190.

(32) Roddick-Lanzilotta, A. D.; McQuillan, A. J. An in Situ Infrared Spectroscopic Investigation of Lysine Peptide and Polylysine Adsorption to $\mathrm{TiO} 2$ from Aqueous Solutions. J. Colloid Interface Sci. 1999, 217 (1), 194-202.

(33) Werner, C.; Zimmermann, R.; Kratzmüller, T. Streaming Potential and Streaming Current Measurements at Planar Solid/ Liquid Interfaces for Simultaneous Determination of Zeta Potential and Surface Conductivity. Colloids Surf., A 2001, 192 (1), 205-213.

(34) McGeachy, A. C.; Dalchand, N.; Caudill, E. R.; Li, T.; Doğangün, M.; Olenick, L. L.; Chang, H.; Pedersen, J. A.; Geiger, F. M. Interfacial Electrostatics of Poly(Vinylamine Hydrochloride),
Poly(Diallyldimethylammonium Chloride), Poly-L-Lysine, and PolyL-Arginine Interacting with Lipid Bilayers. Phys. Chem. Chem. Phys. 2018, 20 (16), 10846-10856.

(35) Picart, C.; Lavalle, Ph.; Hubert, P.; Cuisinier, F. J. G.; Decher, G.; Schaaf, P.; Voegel, J.-C. Buildup Mechanism for Poly(l-Lysine)/ Hyaluronic Acid Films onto a Solid Surface. Langmuir 2001, 17 (23), 7414-7424.

(36) Burke, S. E.; Barrett, C. J. PH-Responsive Properties of Multilayered Poly(1-Lysine)/Hyaluronic Acid Surfaces. Biomacromolecules 2003, 4 (6), 1773-1783.

(37) Richter, R. P.; Brisson, A. R. Following the Formation of Supported Lipid Bilayers on Mica: A Study Combining AFM, QCMD, and Ellipsometry. Biophys. J. 2005, 88 (5), 3422-3433.

(38) Barrantes, A.; Santos, O.; Sotres, J.; Arnebrant, T. Influence of $\mathrm{PH}$ on the Build-up of Poly-L-Lysine/Heparin Multilayers. J. Colloid Interface Sci. 2012, 388 (1), 191-200.

(39) Porus, M.; Maroni, P.; Borkovec, M. Structure of Adsorbed Polyelectrolyte Monolayers Investigated by Combining Optical Reflectometry and Piezoelectric Techniques. Langmuir 2012, 28 (13), 5642-5651.

(40) Choi, J.-H.; Kim, S.-O.; Linardy, E.; Dreaden, E. C.; Zhdanov, V. P.; Hammond, P. T.; Cho, N.-J. Influence of PH and Surface Chemistry on Poly(1-Lysine) Adsorption onto Solid Supports Investigated by Quartz Crystal Microbalance with Dissipation Monitoring. J. Phys. Chem. B 2015, 119 (33), 10554-10565.

(41) Morga, M.; Adamczyk, Z.; Kosior, D.; Kujda-Kruk, M. Kinetics of Poly-l-Lysine Adsorption on Mica and Stability of Formed Monolayers: Theoretical and Experimental Studies. Langmuir 2019, 35 (37), 12042-12052.

(42) Jiang, M.; Popa, I.; Maroni, P.; Borkovec, M. Adsorption of Poly(l-Lysine) on Silica Probed by Optical Reflectometry. Colloids Surf., A 2010, 360 (1), 20-25.

(43) Elgersma, A. V.; Zsom, R. L. J.; Lyklema, J.; Norde, W. Kinetics of Single and Competitive Protein Adsorption Studied by Reflectometry and Streaming Potential Measurements. Colloids Surf. 1992, 65 (1), 17-28.

(44) Kawasaki, K.; Kambara, M.; Matsumura, H.; Norde, W. Protein Adsorption at Polymer-Grafted Surfaces: Comparison between a Mixture of Saliva Proteins and Some Well-Defined Model Proteins. Biofouling 2003, 19 (6), 355-363.

(45) Schaaf, P.; Dejardin, P.; Schmitt, A. Reflectometry as a Technique to Study the Adsorption of Human Fibrinogen at the Silica/Solution Interface. Langmuir 1987, 3 (6), 1131-1135.

(46) Dijt, J. C.; Stuart, M. A. C.; Hofman, J. E.; Fleer, G. J. Kinetics of Polymer Adsorption in Stagnation Point Flow. Colloids Surf. 1990, 51, 141-158.

(47) Dijt, J. C.; Stuart, M. A. C.; Fleer, G. J. Reflectometry as a Tool for Adsorption Studies. Adv. Colloid Interface Sci. 1994, 50, 79-101.

(48) Böhmer, M. R.; van der Zeeuw, E. A.; Koper, G. J. M. Kinetics of Particle Adsorption in Stagnation Point Flow Studied by Optical Reflectometry. J. Colloid Interface Sci. 1998, 197 (2), 242-250.

(49) Norde, W.; Rouwendal, E. Streaming Potential Measurements as a Tool to Study Protein Adsorption Kinetics. J. Colloid Interface Sci. 1990, 139 (1), 169-176.

(50) Scales, P. J.; Grieser, F.; Healy, T. W.; White, L. R.; Chan, D. Y. C. Electrokinetics of the Silica-Solution Interface: A Flat Plate Streaming Potential Study. Langmuir 1992, 8 (3), 965-974.

(51) Zembala, M. Electrokinetics of Heterogeneous Interfaces. Adv. Colloid Interface Sci. 2004, 112 (1), 59-92.

(52) Zembala, M.; Adamczyk, Z. Measurements of Streaming Potential for Mica Covered by Colloid Particles. Langmuir 2000, 16, 1593-1601.

(53) Adamczyk, Z.; Sadlej, K.; Wajnryb, E.; Nattich, M.; EkielJeżewska, M. L.; Bławzdziewicz, J. Streaming Potential Studies of Colloid, Polyelectrolyte and Protein Deposition. Adv. Colloid Interface Sci. 2010, 153 (1-2), 1-29.

(54) Azzam, R. M. A.; Bashara, N. M. Ellipsometry and Polarized Light; North Holland Publishing Company: Amsterdam, 1977. 
(55) Schinke, C.; Christian Peest, P.; Schmidt, J.; Brendel, R.; Bothe, K.; Vogt, M. R.; Kröger, I.; Winter, S.; Schirmacher, A.; Lim, S.; et al. Uncertainty Analysis for the Coefficient of Band-to-Band Absorption of Crystalline Silicon. AIP Adv. 2015, 5 (6), 067168.

(56) Malitson, I. H. Interspecimen Comparison of the Refractive Index of Fused Silica. J. Opt. Soc. Am. 1965, 55 (10), 1205-1209.

(57) Kleimann, J.; Lecoultre, G.; Papastavrou, G.; Jeanneret, S.; Galletto, P.; Koper, G. J. M.; Borkovec, M. Deposition of Nanosized Latex Particles onto Silica and Cellulose Surfaces Studied by Optical Reflectometry. J. Colloid Interface Sci. 2006, 303 (2), 460-471.

(58) Daimon, M.; Masumura, A. Measurement of the Refractive Index of Distilled Water from the Near-Infrared Region to the Ultraviolet Region. Appl. Opt. 2007, 46 (18), 3811-3820.

(59) Etienne, O.; Picart, C.; Taddei, C.; Haikel, Y.; Dimarcq, J. L.; Schaaf, P.; Voegel, J. C.; Ogier, J. A.; Egles, C. Multilayer Polyelectrolyte Films Functionalized by Insertion of Defensin: A New Approach to Protection of Implants from Bacterial Colonization. Antimicrob. Agents Chemother. 2004, 48 (10), 3662-3669.

(60) Morga, M.; Adamczyk, Z. Monolayers of Cationic Polyelectrolytes on Mica - Electrokinetic Studies. J. Colloid Interface Sci. 2013, 407, 196-204.

(61) Hartley, P. G.; Larson, I.; Scales, P. J. Electrokinetic and Direct Force Measurements between Silica and Mica Surfaces in Dilute Electrolyte Solutions. Langmuir 1997, 13 (8), 2207-2214.

(62) Adamczyk, Z. Particles at Interfaces: Interactions, Deposition, Structure; Elsevier: Amsterdam, 2017.

(63) Adamczyk, Z. Kinetics of Diffusion-Controlled Adsorption of Colloid Particles and Proteins. J. Colloid Interface Sci. 2000, 229 (2), 477-489.

(64) Dabros, T.; van de Ven, T. G. M. A Direct Method for Studying Particle Deposition onto Solid Surfaces. Colloid Polym. Sci. 1983, 261 (8), 694-707.

(65) Ohshima, H. Henry's Function for Electrophoresis of a Cylindrical Colloidal Particle. J. Colloid Interface Sci. 1996, 180 (1), 299-301.

(66) Popa, I.; Cahill, B. P.; Maroni, P.; Papastavrou, G.; Borkovec, M. Thin Adsorbed Films of a Strong Cationic Polyelectrolyte on Silica Substrates. J. Colloid Interface Sci. 2007, 309 (1), 28-35.

(67) Cahill, B. P.; Papastavrou, G.; Koper, G. J. M.; Borkovec, M. Adsorption of Poly(Amido Amine) (PAMAM) Dendrimers on Silica: Importance of Electrostatic Three-Body Attraction. Langmuir 2008, 24 (2), 465-473.

(68) Longtin, R.; Maroni, P.; Borkovec, M. Transition from Completely Reversible to Irreversible Adsorption of Poly(Amido Amine) Dendrimers on Silica. Langmuir 2009, 25, 2928-2934.

(69) Michna, A. Macroion Adsorption-Electrokinetic and Optical Methods. Adv. Colloid Interface Sci. 2017, 250, 95-131. 